\title{
Socio-demographic variables and family health: A prospective study of a Katcha in North-central Nigeria
}

\author{
${ }^{*}$ E.0.0. Oleribe BMedSc, MBBS, MPH, MBA, ${ }^{* *}$ D.D. Alasia MBBS, MWACP \\ Departments of ${ }^{*}$ Community Medicine, University of Nigeria Teaching Hospital, Enugu, Nigeria, ${ }^{* *}$ Medicine, \\ University of Port Harcourt Teaching Hospital, Port Harcourt, Nigeria
}

\begin{abstract}
Background: Healthy families are vital prerequisites for a stable society and economic development of the community. The health status of families and communities is influenced by several sociodemographic variables such as educational status, marital pattern and gender relationships. The objective of this study is to examine the effect of certain sociodemographic variables on the health status of a rural community in Northern Nigeria.
\end{abstract}

Method: A prospective survey over a six month period, which commenced in May 2005, was done in rural primary health care centre in Katcha local Government area of Niger state. All consecutive parents either male or female of children seeking care in the health center who gave consent to participate in the survey were recruited. A structured researcher administered questionnaire was used in sourcing data. Data was analyzed using Microsoft Excel version 2003.

Results: A total of 608 parents comprising 302 (49.67\%) male and 306 (50.33\%) females (M: $F=$ 1:1.01) were surveyed. Of these $78.48 \%$ females were uneducated compared to only $41.83 \%$ males. While most males were gainfully employed, $20.86 \%$ of females were full time housewives. Polygamy was the predominant marital pattern. The findings indicate that women in the community were socially disadvantaged compared to males.

Conclusion: There is a significant socio-economic gap which puts females at a disadvantage in the rural community surveyed. Bridging this Socio-economic gap between men and women in rural communities will help improve the health status in our rural communities.

KEYWORDS: Family health; Gender equity; Nupe; Nigeria.

Paper accepted for publication 17th June 2006.

\section{INTRODUCTION}

The Health status of families and by extension of communities is influenced by several sociodemographic factors ${ }^{1}$. Factors such as the literacy level, marital patterns, family income and gender roles and relationship have been shown to influence important health indices such as infant and under five mortality and maternal mortality ${ }^{1,2}$.

Recent reports reveals that two-third of the 799 illiterate people in the world are women and providing girls one extra year of education beyond the average boosts eventual wages by 10 to 20 percent $^{2}$. Achieving gender equality and women's and girls' empowerment requires addressing a complex web of discrimination and disadvantages that women face throughout the world. However, the emphasis on women in much of the gender literature has left the male perspective as the missing link to a true gender approach ${ }^{3}$.Far from arguing that the focus should be only on men, this paper seeks to identify the socio-demographic variables that have negative effect on family health such as the gender gap; as the reversal of such trends will be for the overall benefit of the society.

\section{METHOD}

Katcha is one of the 25 local government areas of Niger state, Nigeria; located about $170 \mathrm{~km}$ away from Minna, the state capital. Majority of inhabitants are of Nupe extraction.

In May 2005, a prospective survey was commenced in a rural primary health care clinic in this community and all consecutive parents of children who came to the hospital for medical care as well as all married adults who needed medical assistance who came to the clinic within the first six months (i.e. May through October 2005) were recruited into the study. They were encouraged to complete a researcher administered questionnaire and completed questionnaires were analyzed using standard statistical methods and inferences drawn.

\section{RESULTS}

Of 608 adults who were surveyed, there were 302 male and 306 females with a male/female ratio of 1:1.01. The women who were surveyed were not necessarily the wives of the men included in the study. Age was not computed because majority of the respondents were ignorant of their true age.

\section{Educational Status}

Majority of the respondents $365(60.03 \%)$ had not 
received any formal education. Majority of respondents without formal education were women $237(64.9 \%)$, while the uneducated men were $128(35.1 \%)$ of people with no formal education. Two hundred and thirty four respondents constituting (38.5\%) of total respondents had received formal education, with 124 respondents with primary education, 75 with secondary education and 44 with tertiary education constituting $52.9 \%$, $32.1 \%$ and $18.8 \%$ of educated people respectively. Women only made up $27.8 \%$ of educated respondents. This showed the educational disadvantage of women in the community. There was a significant difference between the educational level of men and women $\left(X^{2}=\right.$ $85.07, P<0.001)$. The results on the educational status are shown in Table I.

Occupational activity of respondents:

The occupational activity of the respondents ranged from farming which was the predominant occupation by $248(40.8 \%)$ of respondents, to trading in $172(28.2 \%)$, public service $70(11.5 \%)$, artisans $30(4.9 \%)$, students $19(3.1 \%)$, private entrepreneurs $6(0.9 \%)$ and 63 $(10.4 \%)$ without any occupation. All the 63 respondents who had no occupational activity were women. Women were more involved than men in trading and almost equally involved in farming as men. There was a significant difference in the occupational involvement of both gender $\left(x^{2}=150.4, P=0.00\right)$. The finding on occupational activity is shown in Table II.

Marital pattern.

Most married men in the community were polygamous, with the uneducated respondents having more wives then the educated respondents. (See Table III).

The influence of other socio-demographic factors such as occupation, educational status, and religion on family indices such as the number of wives per male, the number of children per male and female is shown in Table III.

Other findings in the survey are the rate of child deaths among females surveyed with an average of 0.95 child death per female.

\section{Table I. Educational qualifications of respondents}

\begin{tabular}{lll}
\hline Level of Education & Male & Female \\
\hline No formal education & $128(41.83)$ & $237(78.48)$ \\
Primary education & $83(27.12)$ & $41(13.58)$ \\
Secondary education & $57(18.63)$ & $18(5.96)$ \\
Tertiary education & $38(12.42)$ & $6(1.99)$ \\
Total & $306(100.0)$ & $302(100.0)$ \\
$X^{2}=85.07, \mathrm{P}<0.001,(\%)$ &
\end{tabular}

Table II. Occupational activities of respondents

\begin{tabular}{lll}
\hline Occupation & Male & Female \\
\hline No occupation & Nil & $63(20.86)$ \\
Trading & $62(20.26)$ & $110(36.42)$ \\
Farming & $131(42.81)$ & $117(38.74)$ \\
Public servants & $63(20.59)$ & $7(2.32)$ \\
Artisans & $28(9.15) 2(0.66)$ & \\
Students & $17(5.56) 2(0.66)$ & \\
Private entrepreneurs & $5(1.63) 1(0.33)$ & $302(100.0)$ \\
Total & $306(100.0)$ & \\
\hline
\end{tabular}

$X^{2}=150.4, P=0.00(\%)$

Table III. Socio-demographic factors and paternal related family statistics

\begin{tabular}{llllll}
\hline No of wives & & W/M & No of children C/M & C/F \\
\hline Education & & & & & \\
No education $=128$ & 240 & 1.86 & 978 & 7.64 & 4.08 \\
Educated=178 & 300 & 1.69 & 975 & 5.48 & 3.25 \\
Occupation & & & & & \\
Trading=62 & 100 & 1.61 & 323 & 5.21 & 3.23 \\
Farming=131 & 244 & 1.86 & 970 & 7.40 & 3.98 \\
Public servants=63 & 111 & 1.76 & 433 & 6.87 & 3.90 \\
Artisans=28 & 53 & 1.89 & 144 & 5.14 & 2.72 \\
Students $=17$ & 22 & 1.29 & 49 & 2.88 & 2.23 \\
Private Entn=5 & 10 & 2.00 & 34 & 6.80 & 3.40 \\
Religion & & & & & \\
Christianity=46 & 53 & 1.15 & 214 & 4.65 & 4.04 \\
Moslem=260 & 487 & 1.87 & 1739 & 6.69 & 3.57 \\
Tribe & & & & & \\
Nupen $=237$ & 435 & 1.84 & 1599 & 6.75 & 3.68 \\
\hline
\end{tabular}

Where $\mathrm{M}=$ Male, $\mathrm{W}=$ Wives, $\mathrm{F}=$ Female and $\mathrm{C}=$ Children

W/M (wife per male), C/M (children per male), C/F (children per female)

\section{DISCUSSION}

Gender crisis came in the forefront of international politics in the mid twentieth century, with women decrying their marginalization and oppression in all spheres of human endeavor.

Although about equal number of males and females were involved in the study, while less than half of the male population lacked any form of education, more than three-quarter of the female population were uneducated. Similarly, while every male respondent was engaged in one occupational activity or the other, more than 20 percent of the females were fully economically dependent having no identifiable occupation. Although the study population was 
comparable in terms of tribe and religion, there was a significant difference in terms of education and occupation $(P<0.001)$. This finding shows how great the gap is between men and women since education and occupation are major indices of development and empowerment.

Furthermore, significantly more males had higher education, better jobs and were involved in pubic service. This findings show the marked socio-economic disadvantage of women in the community surveyed. The high level of ignorance and polygamy also manifest in high maternal birth rates, high pregnancy wastages and high childhood deaths. For instance, uneducated males had more wives and children per man (1.86 and 7.64 respectively), while their wives had more children per woman (4.08). Similarly, male farmers had more wives and children per man ( 1.86 and 7.40 respectively) and their wives had more children per woman (3.98). This is worsened by the fact that although the economy of many tropical countries is still tied to agriculture and agricultural workers are the main support of economic and social process, unfortunately there are no provisions for their health as a specific occupational group ${ }^{1}$. This community lacks the services of a qualified medical practitioner, a government owned hospital and other related facilities. Family planning knowledge was also low and primary health care is not programmed to meet their needs, as most public health centers remain closed on days and periods when they are free to access their services.

However, while the male Moslems had more wives and children per man, their wives had fewer children than the Christian women. This may be because they have more than one wife. However another study in the locality has shown that women in polygamous homes have more pregnancy wastages and childhood deaths than their counterparts in monogamous homes. Since only living children were analyzed, it may not therefore be surprising to discover that more children of the Christian monogamous women survived. That males of Nupe tribe had more wives and children and their wives had more children confirms that there is high reproductive potential in this district. Thus to empower women, they must be educated and given economically enhancing jobs.

This is because studies have shown that maternal education seems to make a difference in the mothers' psychological well-being ${ }^{4}$. But despite the International Conference on Population and Development (ICPD) of $1994^{5}$ where international health advocates, planners, and policymakers agreed that special efforts should be made to stress men's responsibility in female education, family planning and reproductive health, and to promote their involvement in preventing HIVISTDs and unwanted and high-risk pregnancies, little efforts has actually being invested to get the men really involved. $A$ significant number of men attributed their lack of involvement in family planning (and female education) to the fact that they were not included in counseling and education in the past ${ }^{6}$. Now that HIVIAIDS is threatening most polygamous homes, more attention must be paid on male involvement in gender issues.

Even though men in many cultures throughout the world determine whether their wives and/or sex partners will use contraception, family planning information and services in Africa are not targeted to men. Services are instead traditionally presented within the context of maternal and child health ${ }^{6}$. To achieve the millennium development goals, this must change. Moreover, the success of seminars on male involvement demonstrate how eager men are to learn about contraception and how it can improve the lives of their families. The time has come to acknowledge the important male role in family planning, female education and utilization of health care services.

\section{CONCLUSION}

There is an urgent need to bridge the education and health service provision gap between urban and rural areas as well as between the educated and the uneducated. This is a primary requirement if the plans to safe guard the lives and wellbeing of women will ever be realized.

Once this is achieved, men should then be involved in all programmes targeted at female education, reproductive health and empowerment, since they are the major family decision makers. This will within a short time lessen the gaps in education and occupation between men and women, as well as make our families healthier and more psycho-dynamically balanced.

\section{REFERENCES}

1. Okojie OH, Wagbatsoma VA, Ogbeide O, Isah EC, Chiwuzie J. Health status of farmers in rural community. Edo State, Nigeria. Niger Med J 1996; 30(3):127-129

2. WHO. The Millennium Development Goals (MDGs) Facts at a glance. 1211 Geneva 27 Switzerland. 2005.

3. Ghoraveb F, Villarreal M. TSS Thematic workshop on male involvement in sexual and reproductive health programs and services. Rome, Italy. Nov1998:9-13.

4. Jackson AP. The effects of non-resident father involvement on single black mothers and their children. Soc Work 1999; 44(2):156-66.

5. Hawkes S. Providing sexual health services for men in Bangladesh. SexHealth Exch 1998; (3):14-5.

6. Mason K, Lyman P. Not for women only: child-spacing clubs for Malawian men. AVSC News 1992; 30(4):4. 